\title{
The Long-Term Impact of the Electorate on the Swiss Electricity Market Transition
}

\author{
Raphael Klein and Matthias Finger
}

\begin{tabular}{|c|c|c|}
\hline \multicolumn{3}{|c|}{ Contents } \\
\hline 1 & Introduction..$\ldots \ldots \ldots \ldots$ & 138 \\
\hline \multirow[t]{3}{*}{2} & The Research Up to Now ............ & 140 \\
\hline & 2.1 Modelling Electricity Markets. & 140 \\
\hline & 2.2 Policy Process Theories ......... & 142 \\
\hline \multirow[t]{4}{*}{3} & The Hybrid Electricity Model.. & 143 \\
\hline & 3.1 The Electricity Model .......... & 143 \\
\hline & 3.2 The Policy Emergence Model. & 147 \\
\hline & 3.3 The Hybrid Model ............... & 148 \\
\hline \multirow[t]{5}{*}{4} & Experiments, Simulations and Results & 149 \\
\hline & $4.1 \quad$ Scenarios $\ldots \ldots \ldots \ldots \ldots \ldots \ldots \ldots$ & 149 \\
\hline & Model Initialization .............. & 149 \\
\hline & Model Simulation ............ & 150 \\
\hline & 4.4 Results ............... & 150 \\
\hline \multicolumn{3}{|c|}{ Discussion ... } \\
\hline 6 & Conclusion .... & 156 \\
\hline & ferences ....... & 157 \\
\hline
\end{tabular}

\begin{abstract}
The Swiss government, through its Energy Strategy 2050, is engaged on a path to transition Switzerland to become a carbon-neutral country by the year 2050 . In this chapter, we look at the impact that the electorate can have on this transition and on the Swiss electricity market. This is done using hybrid agent-based modelling. We model the Swiss electricity market and we add to this a model of the policymaking process. This allows us to study which policy instruments are more likely to be implemented depending on the Swiss electricity market progression and on the policy actors' interests. The results have shown that the electorate has a limited impact on the policy chosen and on the electricity market. Overall, an environmentally conscious electorate leads policy actors to select the carbon tax as a policy more often. This, however, has the adverse effect to increase the electricity price and increase import dependency in winter. In high demand growth scenarios, the carbon
\end{abstract}

\footnotetext{
R. Klein $(\triangle) \cdot$ M. Finger

EPFL, CDM-MIR, Lausanne, Switzerland

e-mail: r.klein-1@tudelft.nl; matthias.finger@epfl.ch 
tax policy is not sufficient to stem the construction of gas turbine power plants. We also show that because the electricity model does not consider an extended demand response option or technology advancement, the knowledge gained from this model is limited. This drives the behaviour of the model into scenarios which are unlikely to happen, such as a large increase of the gas turbine power plants. Overall, we conclude that, in their current form, even with an environmentally conscious electorate, the electricity market conditions do not allow Switzerland to reach its emissions targets.

\section{Introduction}

On 21 May 2017, the Swiss population voted for the revised Federal Energy Act, also dubbed Energy Strategy 2050 (ES2050). ${ }^{1}$ With the ES2050, the government pledged to shut down all nuclear power plants, to increase the amount of investment in renewable energy such as solar, wind and geothermal, and to increase electricity efficiency throughout the economy. Beyond this, in August 2019, the government also set the goal for Switzerland to be carbon-neutral by $2050 .{ }^{2}$ In Switzerland, most of the electricity production is already low-carbon. In 2018, a majority of $55 \%$ of the electricity was produced by hydropower plants. The rest was produced by nuclear power plants (36\%) and a mix of solar, wind, biomass and thermal power plants $(9 \%){ }^{3}$ However, the rest of the energy sector is powered mostly by fossil fuels.

The Swiss electricity mix is bound to change in the coming years. Nuclear power plants are to be shut down relatively soon. Promoted by the government, efficiency measures and investments in renewable energy sources are meant to bridge the gap in electricity production. Additionally, more imports of electricity from neighbouring countries could also be used if that were to be needed. The current goals of the government are to see the renewable energy supply reach $40 \%$ by 2050 , on top of existing hydropower production. ${ }^{4}$ These targets were designed to achieve goals set by the Federal Council that wants to see Switzerland carbon-neutral by 2050. ${ }^{5}$ Reaching these targets would require a drastic increase in the amount of solar and wind production, along with the wide-scale adoption of geothermal power wherever it is possible.

Additionally, when it comes to electricity production, Switzerland has strong seasonal variations in electricity supply. The demand in winter is higher than the supply; therefore, imports are often needed from neighbouring countries.

\footnotetext{
${ }^{1}$ Swiss Federal Office of Energy (2018a).

${ }^{2}$ RTS (2019).

${ }^{3}$ Swiss Federal Office of Energy (2018b).

${ }^{4}$ Swiss Federal Office of Energy (2019).

${ }^{5}$ Wuthrich (2019).
} 
Meanwhile, there is a surplus of electricity in the summer leading to the export of the Swiss electricity production. A lot of this is driven by the behaviour of hydroelectric plants. In the future, with the current renewable energy production goals, this seasonal imbalance could be further reinforced with a higher deficit in winter, rendering Switzerland more dependent on its neighbours for its security of supply for parts of the year.

Future electricity demand scenarios also need to take into account the electrification of the energy system with a potential growth in demand in the electricity system due to a shift in energy sources in the heating and mobility sectors. At the moment, the electricity production sector accounts for only one third of total Swiss energy consumption, with another third of the energy used for heating and the last third used for mobility. A large shift of energy sources in both these sectors is needed to achieve the carbon neutrality goals set by the government. But this could lead to significant electricity demand growth even if there is an increase in efficiency measures.

So far, the population has been keen on a sustainable transition, but politicians have been slower to follow. Recent parliamentary elections in 2019 have shown that the composition of the Swiss parliament has been affected by this upswell in voters' environmental concerns. However, it remains unclear how this will affect policymaking within the country in the future. More importantly, it is unclear what impact a change in the belief of the policymakers will have on the Swiss electricity sector considering the current policies that are available. This chapter aims at understanding exactly this: What impact can the Swiss electorate have on the Swiss electricity system and its transition?

A hybrid model is used to answer this question. This model is a combination of a Swiss electricity market model and a model of the policy-making process. Each of these models is based on previous work with the Swiss electricity market model being a converted existing system dynamics model ${ }^{6}$ and the policy-making process model taking inspiration from a forthcoming paper by Klein. ${ }^{7}$ This hybrid modelling approach enables the endogenisation of the policy-making process in a sociotechnical system simulation for the first time.

In this chapter, the research that has been performed when it comes to the modelling and simulation of electricity markets and of the policy-making process is presented in Sect. 2. A description is then provided of the hybrid model in Sect. 3. In Sect. 4, an outline of the experiments that were performed with the model is given and the results of the simulations are presented. Section 5 discusses the implications of the results and the conclusions that can be drawn from them. Finally, in Sect. 6, the paper is concluded and an outline of the work that remains to be done in the future is given.

\footnotetext{
${ }^{6}$ Van Baal (2016, 2019a)

${ }^{7}$ Klein et al. (forthcoming).
} 


\section{The Research Up to Now}

The hybrid approach that is pursued in this chapter is novel; however, the study of electricity markets using simulation and the study of the policy-making process are each not new developments in the literature. A high number of electricity market models are present throughout the literature. They were built with the aim to answer specific research questions and are often tailored to their geographic specificities. As for the policy-making process, policy theories have been developed and detailed over the past decades to study this process. A forthcoming paper by Klein has also presented an approach where the theories of the policy process can be used to establish a common language for simulation modellers that can in turn be used to craft models of the policy-making process. ${ }^{8}$ These are all detailed in this section.

\subsection{Modelling Electricity Markets}

Studies of electricity markets using simulation are common throughout the literature. As early as the late 90's, Ford ${ }^{9}$ looked at the construction cycles in the western US electricity market using system dynamics. ${ }^{10}$ This study concluded that the construction cycles can lead to major changes in market prices. It also highlighted how such problems could be dealt with using a constant capacity alongside the market clearing price.

Since then, studies have varied in focus, geographical region, scope, and methods. This includes looking at fuel mix diversification incentives using a mean-variance portfolio optimisation approach. ${ }^{11}$ It also includes looking at nuclear energy policy in Belgium after the Fukushima nuclear accident using system dynamics. $^{12}$ Other models focused on capacity mechanisms. ${ }^{13}$ In the case of Bhagwat et al., ${ }^{14}$ EM-Lab, an agent-based model, was used to investigate a number of different research questions including those related to capacity mechanisms. ${ }^{15}$ Finally some models were part of much larger projects looking at transitions in general. In the case of Trutnevyte et al., ${ }^{16}$ the hybrid model studied was built from a

\footnotetext{
${ }^{8}$ Klein et al. (forthcoming).

${ }^{9}$ Ford (1999).

${ }^{10}$ Sterman (2001).

${ }^{11}$ Roques et al. (2008).

${ }^{12}$ Kunsch and Friesewinkel (2014).

${ }^{13}$ Bhagwat et al. (2014); Bhagwat (2016); Bhagwat et al. (2016); Chao and Lawrence (2009); De Vries and Heijnen (2008).

${ }^{14}$ Bhagwat et al. (2014).

${ }^{15}$ De Vries et al. (2013).

${ }^{16}$ Trutnevyte et al. (2014).
} 
number of other models. The model was used to study storylines within the transition of the UK power system.

In a lot of cases, these models are built for the purpose of exploring current or future policies and they assess their impact individually. In the case of Kunsch and Friesewinkel, ${ }^{17}$ for example, policies were embedded directly into the system dynamics model and tested for a set of alternative policies. These policies were tested against one another and the results were compared to see what outcomes were obtained for each of the policies. A similar approach was used in Fagiani et al., ${ }^{18}$ where the dynamic interactions between two different policies were tested. In this case, the policies were adaptive, therefore taking information from the system to adjust themselves.

The Swiss electricity market has also been studied using a number of different simulation methods. Densing et al. ${ }^{19}$ have looked at a number of these studies and compared the resulting scenarios. In their paper, results from a number of different studies from various organisations that have used a variety of modelling approaches were compared. The goal was for stakeholders to better understand the impact of their modelling assumptions. One of the results of this paper was to show that, overall, the different studies that have been used over the years result in a wide array of scenarios that are deeply influenced by their underlying assumptions.

In separate studies, Ochoa and Van Ackere, Van Ackere and Ochoa, and Osorio and Van Ackere $^{20}$ have also studied the Swiss electricity market using system dynamics models. Ochoa and Van Ackere ${ }^{21}$ focused on the need for policies to limit the dependence on imports and to foster capacity expansion. This was illustrated for a number of different scenarios, some of which have now come to pass. Van Ackere and Ochoa $^{22}$ modelled the Swiss hydroelectric power plants using system dynamics to better study how different production policies impact production and price patterns. This is important as Switzerland is heavily influenced by its hydroelectric power plant park. Finally, Osorio and Van Ackere ${ }^{23}$ looked at the impact of the nuclear phase-out and the addition of renewable energy sources into the market on the electricity mix. The outcomes showed that the removal of nuclear energy is mostly replaced by solar production and imports, along with a rise of the electricity price.

Separate studies have also been ongoing at the Paul Scherrer Institute (PSI). ${ }^{24}$ The model used in this case is the Swiss TIMES ${ }^{25}$ model. This model is a large linear

\footnotetext{
${ }^{17}$ Kunsch and Friesewinkel (2014).

${ }^{18}$ Fagiani et al. (2014).

${ }^{19}$ Densing et al. (2016).

${ }^{20}$ Ochoa and Van Ackere (2009); Van Ackere and Ochoa (2010); Osorio and Van Ackere (2016).

${ }^{21}$ Ochoa and Van Ackere (2009).

${ }^{22}$ Van Ackere and Ochoa (2010).

${ }^{23}$ Osorio and Van Ackere (2016).

${ }^{24}$ Kannan and Turton (2011, 2012, 2013); Paul Scherrer Institute (2012).

${ }^{25}$ The Integrated MARKAL EFOM System.
} 
programming optimisation model made of a number of modules. It was used to study the electricity system, but was not limited to it, also looking at the different sector couplings. Within this model for example, Kannan and Turton studied different technological pathways and their impacts on the overall market. ${ }^{26}$

Overall, simulation and modelling has been an approach that has been used extensively to study electricity markets, including the Swiss market in particular. And for the most part, the use of policies is exogenous within these models, that is, the policy selection process is not integrated within the electricity market models. In the present chapter, we propose to extend this body of literature by looking at a model that considers the electricity market but also the policy-making process that is followed to select the policies to be implemented.

\subsection{Policy Process Theories}

There are a large number of theories of the policy process within the literature. ${ }^{27}$ These theories help provide insights into all aspects of the policy process, whether it concerns the actors and their behaviours, the steps that are followed within the process, or the differences that can be found upon implementation of policies. One of the strengths of these theories is that each theory looks at a different part of the process. For example, the theory of the policy cycle focuses on the steps that the policy process follows. ${ }^{28}$

In a forthcoming paper, Klein has presented a common language based on a number of theories that can be used to model and simulate the policy-making process. ${ }^{29}$ The paper argues why such a model can be useful and the present chapter is one such example. Because of the disparities in the focus of the different theories, it is impossible to use one theory to simulate the entire policy process. It is not possible to combine all of the theories for simulation either, as the theories can sometimes be incoherent, overlapping or lack specifics on how certain parts of the policy process work. The common language is meant to remedy these issues by providing a specific language to model these theories. This language is suggested by the authors, but it is in no way the only approach possible. It is based on the theory of the policy cycle, ${ }^{30}$ the multiple streams framework, ${ }^{31}$ and the advocacy coalition framework. ${ }^{32}$ It is organised along four main elements which are: time, the policy arena, the agents and the interactions. These are detailed below.

\footnotetext{
${ }^{26}$ Kannan and Turton (2013).

${ }^{27}$ Sabatier (2007).

${ }^{28}$ Jann and Wegrich (2007).

${ }^{29}$ Klein et al. (forthcoming).

${ }^{30}$ Jann and Wegrich (2007).

${ }^{31}$ Zahariadis (2007).

${ }^{32}$ Sabatier (1987).
} 
Time is the first key element considered. It is required to define a sequence for the policy process. This is needed for the simulation. A computer requires a sequence of steps to perform a simulation. It cannot operate events that happen at the same time. One process that can be considered is one that follows the theory of the policy cycle for example. This would include steps like the agenda setting, the policy formulation, the policy implementation and the policy evaluation.

The policy arena is the second key element. The policy arena defines boundaries for the model that is studied. The selection of a policy arena leads to the selection of the broader topic of the simulation. The policy arena also defines geographical boundaries. From this, the modeller can select the appropriate agents but also the policies and issues that should be discussed by the agents within the model.

The agents and their specific roles come next. Different roles can be considered within the policy-making process. For example, the policymaker's role is always included as it selects the policy instruments. But other roles like the media, the electorate or policy entrepreneurs can sometimes be omitted depending on the research questions that the model is used for. Different policy arenas might also call for specific and more detailed roles for the agents. Beyond their roles, agents also have a belief system. This belief system is a representation of the environment for the agents. It is what the agents use to choose the policy instruments to be implemented.

Finally, the fourth and last key element is related to interactions. First, there are interactions between the agents and the environment. The environment informs the agents on their beliefs. The flip side is that the policymakers can affect the environment by implementing policies. Beyond this, agents can also influence one another on their beliefs in the hope to advance their respective interests. According to the theories, they can also assemble into coalitions to further advance their interests. A wide array of strategies and behaviours can be included within the modelling of the policy process.

\section{The Hybrid Electricity Model}

To study the impact of policymaking on the Swiss electricity market, a hybrid modelling approach is used. This approach uses an already verified and validated electricity model along with a model of the policy process that has been demonstrated and tested through a theoretical approach. In this section, we detail how the hybrid model that uses both models was constructed. We first detail each of the models separately, before outlining how they were connected to one another.

\subsection{The Electricity Model}

Numerous electricity models have already been built, tested and used over the years. This is also the case for the study of the Swiss electricity market: van Baal has built 
one of these models using a system dynamics modelling approach. ${ }^{33}$ The model was upgraded to a hybrid agent-based/system dynamics model to better consider the investment portion of the electricity market and to study the potential for a strategic reserve in Switzerland. ${ }^{34}$

For the purpose of this chapter, we re-use the same modelling formalisation and assumptions. The model that was built is one that was entirely based on the one presented in van Baal $^{35}$ but that was implemented into an agent-based modelling paradigm. Similarly, the inputs that are used to initialise and historically validate the model are the same. The main reason for this new implementation of the same model was to simplify the connection of this model to the policy-making process model which is also an agent-based model. Additionally, this also leads to a more modular model allowing for easier reusability and the potential for extensions. Finally, the new implementation was made in Python, which is an open source programming language, thus making the model more accessible. ${ }^{36}$

The model is composed of two main modules: the spot market module, where supply is matched to demand, and the investor module, where investors can manage their existing assets and invest in new production assets.

\subsubsection{The Spot Market Module}

The spot market is responsible for matching supply and demand. Demand is comprised of two parts: inelastic demand, which is an input of the model and which represents the Swiss domestic electricity consumption, and elastic demand, which relates to the variable demand that can arise from imports, exports, and from hydroelectric power pumping plants.

The supply is provided by the power plants that are present in the system, the model being initialised with the Swiss electric generation park from 2016 that includes hydroelectric, hydroelectric-pumping, solar, wind, Combined Cycle Gas Turbines (CCGT), waste incineration, run-of-river, and nuclear power plants. Each power plant is instantiated as a separate agent. To participate in the spot market, each asset has a certain bidding price. This calculation is different for all technology types. For wind, solar and run-of-river power plants, the price is equal to the variable costs. For waste incineration, nuclear and CCGT power plants, the fuel costs are added to the variable costs. Depending on the policies, emissions can also add to the costs of the CCGT power plants.

The bidding costs for the hydroelectric and hydroelectric pumping power plants are different as the costs have to take into account the reservoirs, and therefore the

\footnotetext{
${ }^{33}$ Van Baal (2016).

${ }^{34}$ Van Baal (2019a).

${ }^{35}$ Van Baal (2019b).

${ }^{36}$ The model can be found on Github: https://github.com/kleinrap/SwissElectricityMarket.
} 

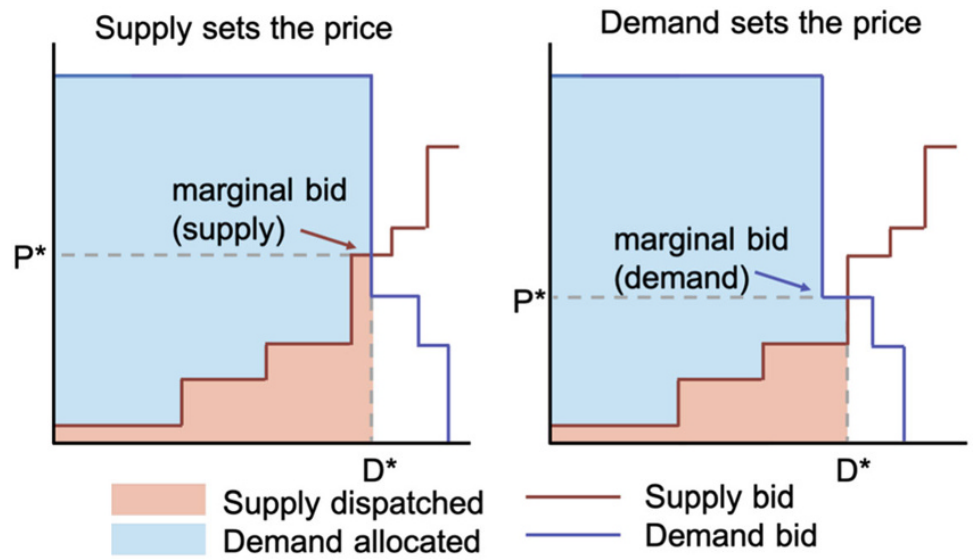

Fig. 1 Merit-order dispatch of the spot market, reproduced with authorisation from Van Baal (2019a)

costs of water. These are referred to as opportunity costs, and the equation that is used to calculate them is based on the work in Van Baal. ${ }^{37}$ It is given by:

$$
P_{b i d}=(1-f) \cdot\left(P_{\text {ref }}-M C\right)+M C
$$

where $f$ represents the amount of energy left in the reservoir, $P_{r e f}$ is the reference price that the investor uses to bid and $M C$ are the marginal costs of the installation (which include the variable costs for a hydroelectric power plant).

This equation was designed in such a way that assets will have some water left in their reservoirs at all times for periods of very high electricity prices. When the reservoir is full, the investor is likely to bid for a lower price and vice versa.

The imports and exports are also an important part of the spot market. First, Switzerland has long-term contracts with France. This consists of options that Switzerland can exercise depending on the spot market price and which are introduced into the model through historical inputs. Beyond this, Switzerland has a certain number of connections with its neighbours that allow it to import or export electricity. Within the model, each country is considered as an agent of its own, and countries can bid on the spot market. That bid is dependent on the net transfer capacity between the two countries and the price is set by the price of electricity in the neighbouring country, which is itself based on a historical yearly profile. Note that these interconnections are also used by the long-term contract for the case of France, an element that can further limit the capacity available for other suppliers.

The spot market, where supply is matched to demand, is operated using a meritorder dispatch algorithm. A graphical illustration of this algorithm is shown in Fig. 1. This algorithm makes sure that there is as much supply as there is demand. The

${ }^{37}$ Van Baal (2016). 
maximum price allowed is the Value of Lost Load (VoLL) and it is set at $3000 \mathrm{CHF} /$ MWh. If the demand cannot be met, then blackouts can occur. Otherwise, supply is added from the lowest bidding price to the highest until the demand and the supply curves intersect. The intersection determines the price of electricity every hour, and it determines the supply that is needed. The price can be determined by demand or supply, depending on how the curves cross. This intersection also helps assign revenues and electricity production to the assets.

\subsubsection{The Investor Module}

The investor module is composed of two main parts: a part where the investors can manage their current assets and a part where investments in new assets can be made. These investments are limited to the solar, wind and CCGT technologies. The assumption is that these are the only viable technological options for Switzerland. The country is planning to retire its nuclear power generation, and, in the current political climate, coal power plants are out of the question.

Investment analyses are performed by the agents on a regular basis. These are done on discrete power plants for each of the three technologies. The investment decision is based on a profitability index, with the assumption that the investors have access to the general market prices along with their respective asset-level data. The profitability index is given as follows:

$$
P I=\frac{N P V}{I C}=\frac{\sum_{n=0}^{N} C_{n}(1+r)^{n}}{I C}
$$

where $C_{n}$ is the cash flow at time step $n, r$ is the discount rate and $I C$ are the investment costs.

After the initial decision to invest, the planned assets go through a number of steps that include planning time, re-assessment of the profitability index, and construction of the asset. These steps can delay the introduction of a new power plant significantly.

Investors can also manage their assets. This happens mostly towards the end of life of the assets. Investors periodically re-assess the profitability of their assets, so they can decide whether they should mothball the asset or keep it online. In cases where the asset is close to its end of life, the investors can also decide on whether to retire and decommission the asset or extend its life, an action that is limited in number. 


\subsection{The Policy Emergence Model}

The policy process model is specified according to the four key elements that were outlined earlier: time, policy arena, agents and interactions. The main choice that is left to the modeller is to decide how much complexity needs to be integrated into each of these elements to answer the research question. In the present case, only a limited amount of complexity is required. This leads to a relatively simple policymaking process model. It is detailed in this section.

For the time element, we consider a two-step policy-making process consisting of an agenda-setting and a policy formulation step. The agenda-setting step is the first step and consists of the agents selecting an issue to place on the agenda to narrow down further discussions. This agenda is then used to limit the policy instruments that can be evaluated for implementation. During the policy formulation step, the policymakers select a policy instrument and implement it with the aim of affecting the outcomes of the electricity model.

The policy arena is the Swiss electricity market model. This policy arena helps define the issues that can be considered within the belief system of the agents. It further limits the agents that can be considered to policymakers that are related to the electricity market. It also helps define the policy instruments that can be considered within this model. The policy core issues that are selected are the environment and the economy, following insights gained from Markard et al. ${ }^{38}$ The secondary issues are extracted directly from the electricity model, along with the policy instruments, which are derived from exogenous parameters. These are detailed in the next section.

For the agents, only two roles are introduced: the policymakers and the electorate. The policymakers are agents that decide what should go on the agenda and what policies should be implemented. They base their decisions on their preferred states and their beliefs for each issue in the belief tree. They focus on the issues that they consider to be the most urgent to deal with, which means issues that have the largest gap between preferred state and belief. The electorate on the other hand can only perform one action: they influence the preferred states of the policy makers. This is a progressive influence that can vary in strength based on the parameters defined by the modeller.

When it comes to the interactions, only three are considered. As outlined in the previous paragraph, the first interaction is the electorate influencing the policymakers. The second and third interactions are then inherent in the construction of the hybrid model: the environment — in the electricity market model—influences the beliefs of the policymakers, and the policymakers influence the electricity market through policy instruments.

${ }^{38}$ Markard et al. (2016). 


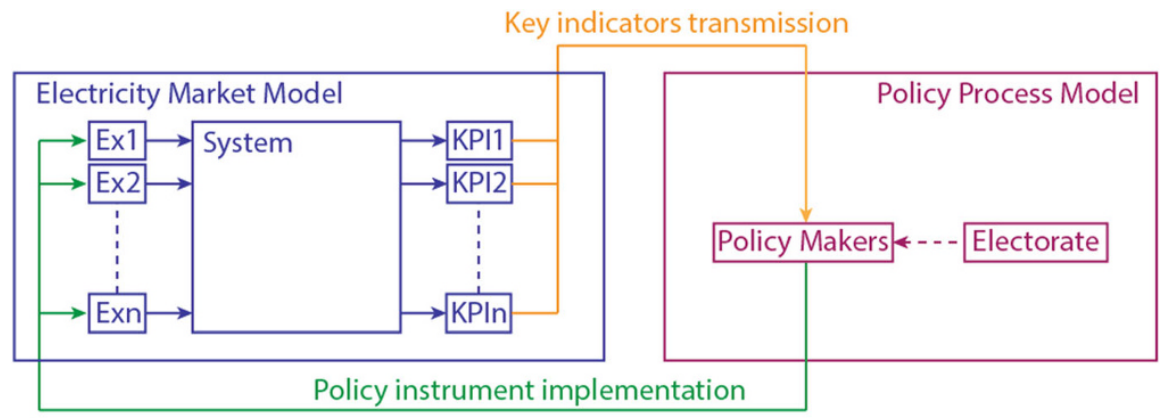

Fig. 2 Conceptual representation of the hybrid model and the interaction between the two models

\subsection{The Hybrid Model}

To study the impact of the policy process on the electricity market, we need to connect both models. How this is done conceptually is illustrated in Fig. 2. The models are connected through one link in each direction. After the electricity model has been simulated for a pre-defined amount of time, a number of key indicators are extracted from the electricity model and used to inform the beliefs of the policymakers. These are indicators that will help policymakers make a decision on what, if any, policy instrument should be implemented such that their preferred states are reached for all their issues. The policy instrument implementation is the second connection linking the policy-making model to the electricity model. Each policy instrument corresponds to a change of a set of exogenous parameters within the electricity model. These changes in turn affect the outcome of the electricity model. Overall, this forms a loop that includes the two models, thus creating a hybrid model.

In the present case, the indicators that are taken from the electricity model to inform the policymakers' beliefs are the following:

- KPI1-The total renewable energy production [MWh]

- KPI2-The year averaged electricity price [CHF/MWh]

- KPI3-The total renewable energy investments as a percentage of the overall investments [\%]

- KPI4-The total domestic emissions [ton]

- KPI5-The total imported emissions [ton]

The policymakers can act through policy instruments that can change the following exogenous parameters:

- Ex1-Solar subsidy [CHF/MWh]

- Ex2-Wind turbine subsidy [CHF/MWh]

- Ex3-Investor's hurdle rate [\%]

- Ex4-Carbon tax on domestic emissions [CHF/ton]

- Ex5-Carbon tax on imported emissions [CHF/ton] 


\section{Experiments, Simulations and Results}

The simulation of the model is used to answer the research question. The scenarios are designed with this in mind. In this section, we also present the results obtained, including main metrics from the electricity market model and the policy selected by the policymakers in the policy emergence model. The results are then analysed to better understand what the impact of the electorate is on the policy makers and whether that influence leads to policy change.

\subsection{Scenarios}

For the construction of the scenarios, we look at varying only two parameters, one in each model: the influence rate of the electorate and the electricity demand growth.

Depending on how strong the electorate influence is, the beliefs of the policymakers will vary at a slower or quicker pace. Varying the strength of the influence can help illustrate a sense of urgency in the general public as we are currently witnessing in the context of climate change for example. We select scenarios where the electorate has zero influence and therefore the policymakers do not change their beliefs, a scenario where the policymakers' beliefs change towards the beliefs of the electorate by $5 \%$ of the difference in both agents' beliefs every round, and a scenario where this change is $50 \%$. This helps represent a range of scenarios with a very weak and a very strong electorate.

The second parameter, the electricity demand growth, is part of the Swiss electricity market model. The demand growth for the electricity sector is so far predicted to be stable or negative in the coming years. ${ }^{39}$ This can be attributed to an increase in efficiency in the heating sector and in general appliances. However, in the future and to meet the carbon neutrality pledge of the confederation, there is an expectation of the electrification of society. This includes the mobility sector using electricity as its main energy source and the building sector. We therefore assume that the growth will remain non-negative. To take into account these scenarios, we look at three scenarios of electricity demand growth: $0 \%, 1.5 \%$ and $3 \%$.

\subsection{Model Initialization}

Both models are initialised following a different approach related to their use. The Swiss electricity market model is initialised with data used previously by van Baal et al. in their work. ${ }^{40}$ This consists of mostly historical data including data on the

\footnotetext{
${ }^{39}$ Swiss Federal Office of Energy (2013).

${ }^{40}$ Van Baal (2019a).
} 
import and export capacity and prices, the demand, and the technology costs. This data was compiled for several years, from 2015 to 2017 . The model simulation itself is run from the year 2016 onwards. Furthermore, it is also important to note that this model was historically validated using this same data.

For the policy-making process model, only the preferred states of the policymakers and the electorate have to be initialised. The number of agents considered does not make a difference regarding the complexity. For the preferred states of the electorate, it was decided to select preferred states that reflect the targets of the Swiss government in 2050, which means carbon neutrality, investments limited only to renewable energy sources and affordable electricity prices. For the policymakers, their initial preferred states were set to the current levels in the model. This assumes that the agents are content with the current levels of the indicators.

\subsection{Model Simulation}

The models are simulated in series in a loop. The electricity model runs on an hourly time step while the policy-making process model is simulated every three years. This means that every 3 years, the electricity model simulation is halted and the policy emergence model is simulated. Once this is done, the policy selected is implemented and the electricity model resumes. This is done for a period of thirty years starting in the year 2016 - due to the availability of historical data to initialise the model. Furthermore, for each combination of scenarios, the hybrid model is repeated fifty times to obtain results from which conclusions can be drawn.

\subsection{Results}

We present the results based on three main figures. In Fig. 3, the monthly averaged electricity price for all of the scenario combinations considered is plotted. Each of the three demand growth scenarios is plotted for each of the electorate influence parameter values. Figure 4 presents the electricity supplied by solar, wind and CCGT power plants. The results are split per growth demand scenario. The demand is also plotted as a reference. Finally, the third figure presents the sum of policies implemented across 50 simulations for the three different electorate influence rates for a demand growth of 3\%. This is presented in Fig. 5 .

Figure 3 shows that prices are bound to go up over time, regardless of the scenario, though this increase is less pronounced for smaller demand growth scenarios. This shows that the price rise is linked to demand growth and not so much to electorate influence. The highest growth in prices is related to the 3\% demand growth scenario as could be expected. In this scenario, Switzerland's demand would roughly double from 10 to $20 \mathrm{GW}$, an additional demand that would have to be fulfilled by a combination of new investments and additional imports from 

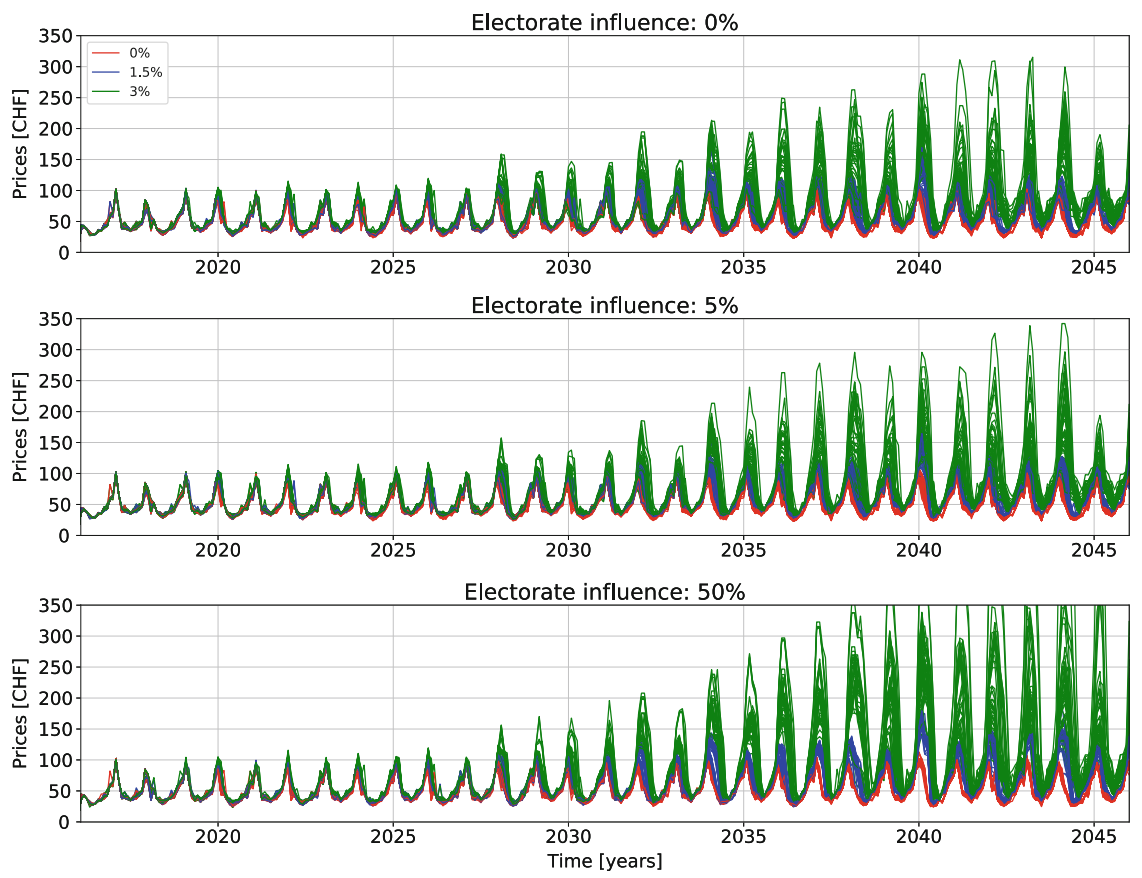

Fig. 3 Monthly averaged electricity prices, split according to the three electorate influence rates and for the three demand growth scenarios

neighbouring countries as shown in Fig. 4. This would imply electrification of a significant share, if not of the entire energy sector. We can conclude from this that prices of electricity across the country will depend heavily on the speed of the electrification in Switzerland and, in some respect, on the speed of efficiency increases as well.

Figure 4 outlines the supply from solar, wind and CCGT, and therefore, by proxy, the investments in those technologies over time. One can see that the difference in the energy mix is mostly driven by demand growth and not so much by electorate influence. In fact, the electorate influence has so little impact on the results that it is difficult to even differentiate the different electorate influence scenarios in the plots. For the scenario with $0 \%$ growth, most of the investments are limited to wind and solar. Note that, within the electricity model, solar and wind each have a cap of installed capacity based on numbers from the Swiss Federal Office of Energy (SFOE), for wind at $2282 \mathrm{MW}$ and for solar at 19,702 MW. It was also assumed that there is no growth in import and export capacity as this would have a large impact on the security of supply and the introduction of CCGT power plants. ${ }^{41}$ There is some investment in CCGT for this scenario, but overall gas plants are not considered financially viable and are therefore avoided. The electricity prices are

${ }^{41}$ Van Baal (2019b). 


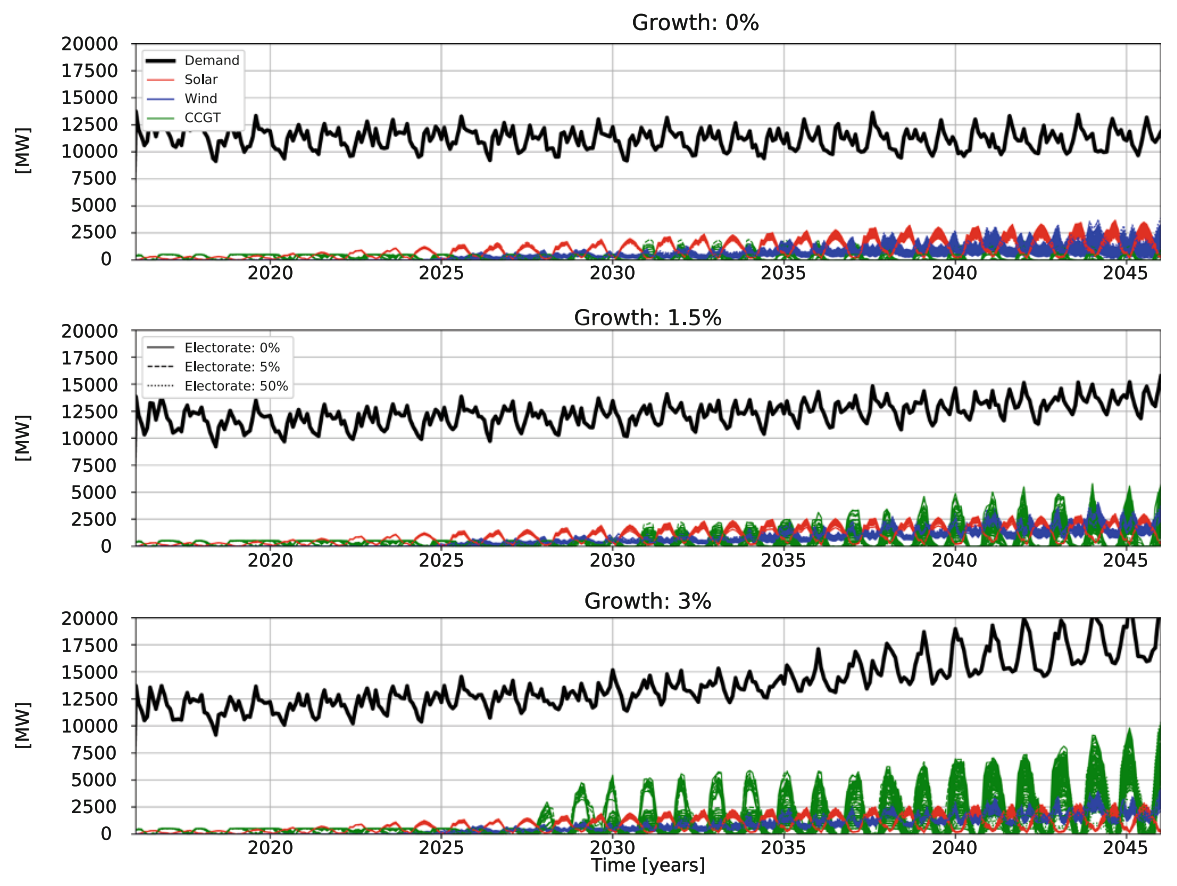

Fig. 4 Overall demand with the electricity supplied by solar, wind and CCGT sources for all scenarios

too low. Things change in the case of the $1.5 \%$ and the $3 \%$ demand growth scenarios. For the $1.5 \%$ scenario, there is a clear investment in CCGT capacity around the time when solar and wind are maxed out. This is justified by an increasing demand and rising prices. For the 3\% scenario, the rise in prices is so quick that investments in CCGT occur early on, even before solar and wind have been maxed out. CCGT is viable early on and is seen as the only possible technology able to bridge the demand gap considering that only a limited increase in imports and exports is possible and considering the other boundaries of the model.

Finally, Fig. 5 is the only figure that describes the outcome of the policy-making process model. The figure was made by summing, for each time step, the policy instrument implemented by the policymakers. This allows us to see what policy instruments are favoured by the policymakers and at which time steps. Only the 3\% demand growth scenario results are presented here because these results provide the most insights. The results for the other scenarios are similar in nature. One can observe that actors overall prefer the use of the carbon tax policy, may it be domestic or foreign. This is the case for all growth scenarios with one difference between them: the timing at which the taxes are imposed. In the case where the electorate has an important influence on the policymakers, the taxes are implemented very early on. In fact, it is the only scenario where the tax is imposed in the second step in 2021. This happens for forty of the fifty simulations. For the other scenarios, where the 


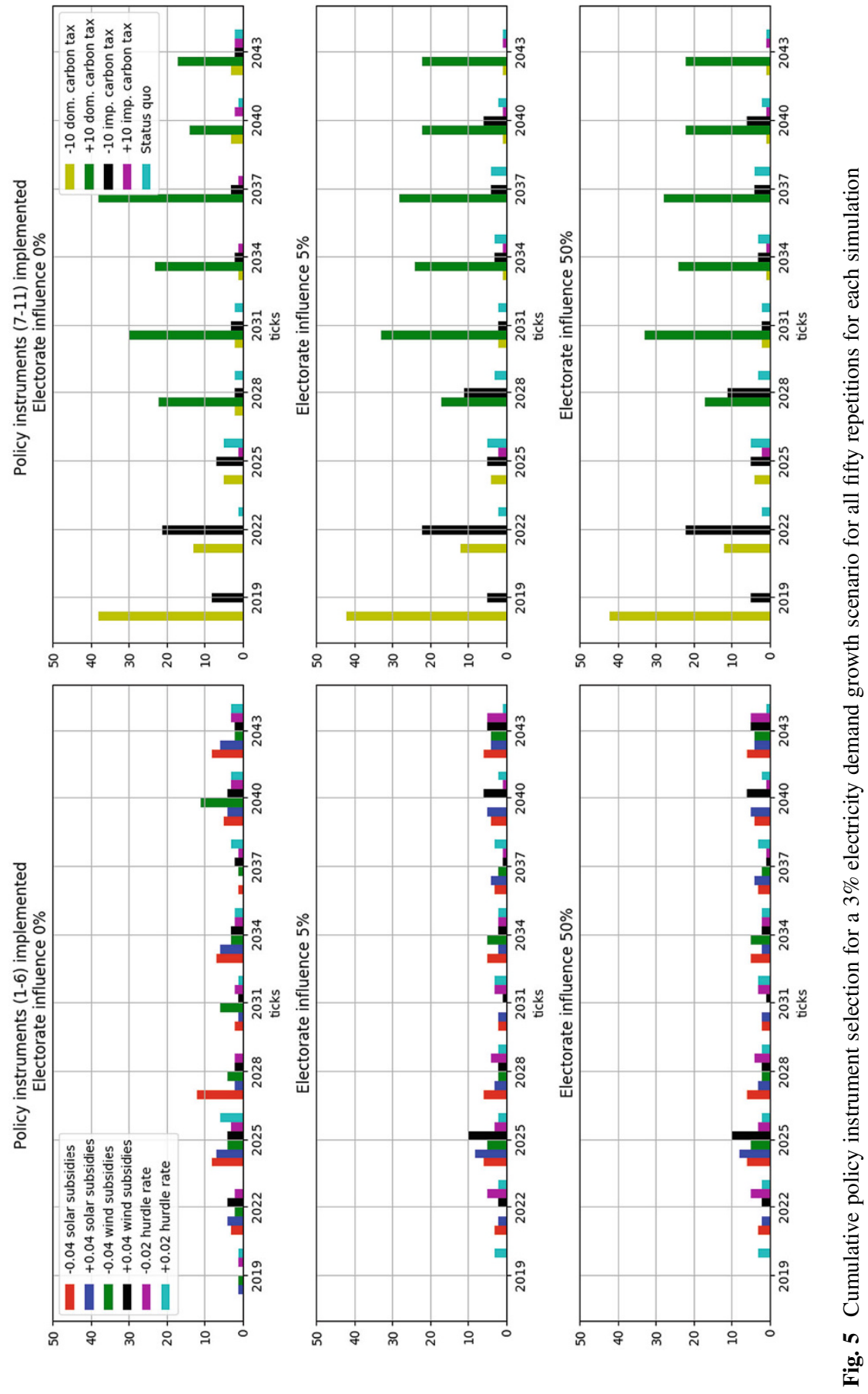


electorate has less or no influence on the policymakers, it takes more time for the tax to be considered. Note that the introduction of the carbon tax is also the main driver for the electricity price increase that is clearly reflected in Fig. 3. All other policies are implemented at a much slower rate throughout the simulations, and when agents implement a subsidy or a change in the investment hurdle rate, it is often balanced out later by an opposite change in that policy, having little long-term impact on the overall simulation. Only the carbon tax is implemented and not removed for all simulations considered.

\section{Discussion}

The main research question of this paper concerned the impact of the electorate on the Swiss electricity system and its transition. The results have shown that the electorate indeed has a large impact on the policymakers. However, its impact on the electricity system as a whole is much more questionable. As shown throughout the results, demand growth has a much higher impact on the outcome of the electricity mix than the electorate. In fact, it seems that the only impact the electorate has is on the prices. The electorate influences policymakers to be more environmentally friendly, which in turn implies the sustained implementation of a carbon tax. However, because of the electricity model's assumptions - a cap on the amount of solar and wind and a maximum net transfer capacity-this cannot result in an increase in solar and wind power plants. It results instead in the additional construction of CCGT plants regardless of the carbon price because of the lack of other possible options. Therefore, an enormous growth in the emissions can be observed. Overall, this suggests that Switzerland would not be able to meet its obligations when it comes to a reduction in emissions if those limits remained firmly in place. In fact, it is possible and likely that Switzerland will have more emissions in 2050 than it has right now if its electricity demand is allowed to grow exponentially.

These results should be put into the broader context of the simplistic approach used for the electricity model. The electricity model is limited to a conventional approach of the electricity market. It does not consider the technological innovation that would accompany the electrification assumed for the high demand growth scenario. This includes the introduction of batteries, demand side management and other innovations that will come as a result of an increased digitalisation. When considered, such innovation could greatly affect the demand curve, even if the demand growth were to reach $3 \%$ annually as is postulated in the most extreme scenario in this paper.

On the other hand, the results are optimistic. They show a large adoption of wind turbines, on the scale that the SFOE has predicted. The current situation has shown that wind turbines currently face strong local opposition in Switzerland and that the goals are not currently met. The results therefore show a situation that would be optimal for the adoption of wind power; but this remains unlikely without more social acceptance, accompanied by significant regulatory and legal change. 
Besides the optimistic increase of wind turbines, the model suggests that a large number of CCGT power plants will be constructed in Switzerland. These results are purely based on economics and do not reflect the politics, or acceptance, of such technology. In fact, it is likely that proposals for the construction of a CCGT power plant would face the same amount of rejection as a wind turbine, if not more. Highlighting this issue, and especially in a $1.5 \%$ or $3 \%$ demand growth scenario, it is important to note that the production stemming from CCGT power plants would need to be filled by other electricity sources. From the results of this model, it is unclear what that could be.

The results also depict Switzerland as a country that is even more dependent, seasonally, on its neighbours. The decrease in nuclear power production, accompanied by more solar power and the potential of demand growth means that Switzerland will be even less able to supply its entire electricity in the winter period and will further depend on its neighbours for its security of supply. This is an issue that is politically sensitive considering the current negotiations between Switzerland and the European Union. ${ }^{42}$ Nonetheless, it is an issue that will become more important as time passes as the results suggest.

Elements related to the policy-making process model have also affected the results. Within the policy-making process model, the policymakers are only able to select one policy instrument at a time. This is an assumption that is made based on insights gained from punctuated equilibrium theory. ${ }^{43} \mathrm{~A}$ different implementation could have seen policymakers negotiating to introduce a policy package that would include a number of different policy instruments. This might affect the results as it could include the introduction of subsidies for solar power plants and an increase of carbon taxes by policymakers. However, considering the net difference between the amount of times the carbon tax policy instruments are selected and the other instruments, it is unlikely that considering such a policy package would make a large difference.

Beyond the potential for policy packages, the policy-making process model used within this paper is inherently simple. In fact, most of the model could have been replaced by one agent whose preferred states change over time and who tests policy instruments, selecting the best and implementing it. One of the reasons for the use of this model was to present a novel approach for the study of socio-technical system simulations. The other reason was the research question. The policy-making model used is sufficient to answer the question.

For other research questions and more policy-focused research questions, the policy-making model can be made to incorporate more complexity. For example, Markard et al. (2016) have shown that coalitions play an important role in the shaping of the electricity market policies. To investigate the impact of coalitions on the electricity system, the policy-making process model would need to incorporate aspects such as coalitions, policy entrepreneurs, agent on agent interactions, and

\footnotetext{
${ }^{42}$ Van Baal and Finger (2019).

${ }^{43}$ Baumgartner et al. (2014).
} 
potential additional elements such as imperfect knowledge transfer. The approach presented here allows for that when needed. However, this complexity increase would bring limitations of its own but would allow for answering many more research questions.

Overall, the study presented here was the first time that such an approach was utilised. This has allowed us to gain a better understanding of the feedback effects between the policy-making process and the electricity system, despite the simplicity of both models. It has also shown that there is room for improvement, mostly through an increase in complexity in either model. Increasing complexity in the electricity model would allow for more insightful results and could help guide the design of new regulations. A more complex policy-making process would allow for more insights on the dynamics between the different coalitions that are present in the Swiss electricity market and for a better understanding of how this might impact policy selection.

\section{Conclusion}

In this paper, we have presented a novel approach to study the Swiss electricity market by also considering the policy-making process. We have presented a hybrid model that combines two agent-based models: one of the electricity market and another of the policy-making process. By connecting these two models we were able to study the impact that the electorate has on the Swiss electricity market through the policy-making process.

Overall, the results show that the electorate has an impact on the electricity market though not necessarily along its goals — or preferred states as they are named in the model. The results also show that despite using a simple policy-making process model, it is the simplicity of the electricity market model that constrains the possible results. The results highlight the fact that the electorate only has a finite amount of influence and that, without the presence of new innovative technologies and the accompanying regulations, the current course is unlikely to allow Switzerland to fulfil its emissions obligations. Moreover, the model demonstrates that the confederation is likely to be seasonally highly dependent on its neighbours.

Within the scope of this model, the policymakers opted in the majority of time for a carbon tax to achieve their goals, may it be on domestic energy supply or on imports. This had the perverse effect to push the prices up. We have shown that the main reason why the actors chose the carbon tax policy instrument was the fact that there were no other good alternatives provided to them-the electricity model does not allow for more effective policy instruments.

In future work, complexity will be added to the electricity market model to allow for the possibility of demand side management and prosumers and to take into account the potential for more batteries within the electrical system. Future work will also expand the research questions that can be answered using this hybrid approach by exploring the impact of coalitions on the Swiss electricity market. 


\section{References}

Baumgartner FR, Jones BD, Mortensen PB (2014) Punctuated equilibrium theory: explaining stability and change in public policymaking. In: Sabatier PA, Weible CM (eds) Theories of the policy process, 3rd edn. Westview Press, Boulder, pp 59-103

Bhagwat P (2016) Security of supply during the energy transition: the role of capacity mechanisms. Dissertation, Delft University of Technology

Bhagwat PC, Iychettira K, De Vries LJ (2014) Cross-border effects of capacity mechanisms. In: 11th International Conference on the European Energy Market (EEM14), 1-5

Bhagwat PC, Richstein JC, Chappin EJ, De Vries LJ (2016) The effectiveness of a strategic reserve in the presence of a high portfolio share of renewable energy sources. Utilit Policy 39:13-28

Chao H, Lawrence DJ (2009) How capacity markets address resource adequacy. In: 2009 IEEE Power \& Energy Society General Meeting, 1-4

De Vries LJ, Heijnen P (2008) The impact of electricity market design upon investment under uncertainty: the effectiveness of capacity mechanisms. Utilit Policy 16(3):215-227

De Vries LJ, Chappin EJ, Richstein JC (2013) EMLab-Generation - an experimentation environment for electricity policy analysis (Version 1.0). Technical report, Delft University of Technology

Densing M, Panos E, Hirschberg S (2016) Meta-analysis of energy scenario studies: example of electricity scenarios for Switzerland. Energy 109:998-1015

Fagiani R, Richstein JC, Hakvoort R, De Vries LJ (2014) The dynamic impact of carbon reduction and renewable support policies on the electricity sector. Utilit Policy 28:28-41

Ford A (1999) Cycles in competitive electricity markets: a simulation study of the western United States. Energy Policy 27(11):637-658

Jann W, Wegrich K (2007) Theories of the policy cycle. In: Fischer F, Miller GJ, Sidney MS (eds) Handbook of public policy analysis: theory, politics, and methods. Routledge, New York, pp 43-62

Kannan R, Turton H (2011) Documentation on the development of the Swiss TIMES Electricity Model (STEM-E). Technical report, PSI

Kannan R, Turton H (2012) Swiss Electricity Supply Options. Energy Economics Group, Laboratory for Energy Systems Analysis. Technical report, PSI

Kannan R, Turton H (2013) A long-term electricity dispatch model with the TIMES framework. Environ Model Assess 18(3):325-343

Klein R, Ashkenazy A, Nikolic I, Bots PWG (forthcoming) Developing a common language of the policy process for modellers. Policy Studies Journal (under review)

Kunsch PL, Friesewinkel J (2014) Nuclear energy policy in Belgium after Fukushima. Energy Policy 66:462-474

Markard J, Suter M, Ingold K (2016) Socio-technical transitions and policy change: Advocacy coalitions in Swiss energy policy. Environ Innov Soc Trans 18:215-237

Ochoa P, Van Ackere A (2009) Policy changes and the dynamics of capacity expansion in the Swiss electricity market. Energy Policy 37(5):1983-1998

Osorio S, Van Ackere A (2016) From nuclear phase-out to renewable energies in the Swiss electricity market. Energy Policy 93:8-22

Paul Scherrer Institute (2012) The new swiss energy policy: Where will the electricity come from? Energie-Spiegel, No. 21 (November)

Roques FA, Newbery DM, Nuttall WJ (2008) Fuel mix diversification incentives in liberalized electricity markets: a mean-variance Portfolio theory approach. Energy Econ 30(4):1831-1849

RTS (2019) La Suisse doit viser la neutralité carbone dès 2050, 28 August 2019. Available at https://www.rts.ch

Sabatier PA (1987) Knowledge, policy-oriented learning, and policy change: an advocacy coalition framework. Knowledge 8(4):649-692

Sabatier PA (2007) Theories of the policy process, 2nd edn. Westview Press, Boulder 
Sterman JD (2001) System dynamics modeling: tools for learning in a complex world. California Manage Rev 43(4):8-25

Swiss Federal Office of Energy (2013) Energieperspektiven 2050. Technical report, available at https://www.bfe.admin.ch

Swiss Federal Office of Energy (2018a) Energiestrategie 2050 nach dem Inkrafttreten des neuen Energiegesetzes. Presentation, available at https://www.bfe.admin.ch

Swiss Federal Office of Energy (2018b) Gesamte Erzeugung und Abgabe elektrischer Energie 2018. Technical report, available at https://www.bfe.admin.ch

Swiss Federal Office of Energy (2019) The energy strategy 2050. Presentation

Trutnevyte E, Barton J, O'Grady Á, Ogunkunle D, Pudjianto D, Robertson E (2014) Linking a storyline with multiple models: a cross-scale study of the UK power system transition. Technol Forecast Soc Change 89:26-42

Van Ackere A, Ochoa P (2010) Managing a hydro-energy reservoir: a policy approach. Energy Policy 38(11):7299-7311

Van Baal PA (2016) Business implications of the energy transition in Switzerland. MSc Thesis, EPFL

Van Baal PA (2019a) Effectiveness of a strategic energy reserve during the energy transition: the case of Switzerland. Competition and Regulation in Network Industries. https://doi.org/10. 1177/1783591719879365

Van Baal PA (2019b) Policy analysis during socio-technical energy transitions: three essays on the Swiss electricity sector. Dissertation, EPFL

Van Baal PA, Finger M (2019) The effect of European integration on Swiss energy policy and governance. Polit Gov 7(1):6-16

Wuthrich B (2019) La suisse décrète la neutralité carbone en 2050. Le Temps (online), 28 August 2019. Available at https://www.letemps.ch/suisse/suisse-decrete-neutralite-carbone-2050

Zahariadis N (2007) The multiple streams framework: structure, limitations, prospects. In: Sabatier PA (ed) Theories of the Policy process, 2nd edn. Westview Press, Boulder, pp 65-69

Raphael Klein is Post-doctoral researcher at the Faculty of technology, Policy and Management at Delft University of Technology, Delft, The Netherlands.

Matthias Finger is Professor at the College of Management of Technology at École Polytechnique Fédérale de Lausanne, Lausanne Switzerland.

Open Access This chapter is licensed under the terms of the Creative Commons Attribution 4.0 International License (http://creativecommons.org/licenses/by/4.0/), which permits use, sharing, adaptation, distribution and reproduction in any medium or format, as long as you give appropriate credit to the original author(s) and the source, provide a link to the Creative Commons license and indicate if changes were made.

The images or other third party material in this chapter are included in the chapter's Creative Commons license, unless indicated otherwise in a credit line to the material. If material is not included in the chapter's Creative Commons license and your intended use is not permitted by statutory regulation or exceeds the permitted use, you will need to obtain permission directly from the copyright holder. 